\title{
Sıralı Küme Örneklemesi ile İki Yığın Ortalaması Farkı İçin Bootstrap Güven Aralıklarının İncelenmesi
}

\author{
Examination of Bootstrap Confidence Intervals for The Difference Between Two Population \\ Means with Ranked Set Sampling
}

\author{
Nurdan YENİAY KOÇER*a, Yaprak Arzu ÖZDEMIR ${ }^{\mathrm{b}}$, Fikri GÖKPINAR \\ Gazi Üniversitesi, Fen Fakültesi, İstatistik Bölümü, 06500, Ankara
}

• Geliş tarihi / Received: 17.11.2019 • Düzeltilerek geliş tarihi / Received in revised form: 19.04.2020 • Kabul tarihi / Accepted: 14.05 .2020

\begin{abstract}
$\ddot{O} z$
Sıralı Küme Örneklemesi (SKÖ), ilgili değişkeni ölçmenin emek, zaman ya da maliyet bakımından zor olduğu ancak bu değişkeni daha düşük maliyetle sıralamanın mümkün olduğu durumlarda kullanılan bir örnekleme tekniğidir. Bu teknikte genellikle sıralamada hata yapılmaması için küme çapının küçük olması tercih edilir. Bununla birlikte, istatistiksel çıkarsamalar yapılırken, test istatistiğinin dağılım bilgisine ihtiyaç duyulur. Örnek çapı yetersiz olduğu için dağılım bilgisinin elde edilemediği ya da dağılım bilgisinin olmadığı durumlarda bootstrap gibi yeniden örnekleme teknikleri kullanılabilir. Bu çalışmada, sıralı küme örneklemesi altında farklı bootstrap örnek seçim yöntemleri ele alınmıştır. Ele alınan yöntemler iki yığın ortalaması farkına ilişkin güven aralığını oluşturmak üzere geliştirilmiştir. Ayrıca Monte Carlo simülasyon çalışması ile örnek seçim yöntemleri bazı simetrik ve çarpık dağılımlar altında güven aralığı kapsama olasılıkları ve genişlikleri bakımından incelenmiştir. Elde edilen sonuçlara göre, en yüksek güven aralığı kapsama olasılıkları standart normal dağılım altında elde edilmiştir. Simetrik olmayan dağılımlarda ise, dağılım simetrik hale geldikçe elde edilen güven aralığı kapsama olasılığının arttığı görülmüştür. Önerilen yöntemlerden 2. yöntem ile elde edilen güven aralığı kapsama olasılıklarının 1. yöntem ile elde edilen güven aralığı kapsama olasılıklarından daha yüksek olduğu görülmüştür. Güven aralığı genişliklerinin ise dağılımın varyansı azaldıkça daraldığı gözlemlenmiştir. Bunun yanında, gerçek veri üzerinde güven aralığı genişliğinin elde edilmesi ile ilgili bir uygulama çalışması yapılmıştır.
\end{abstract}

Anahtar kelimeler: Bootstrap, Güven Aralığı Kapsama Olasılığı, Sıralı Küme Örneklemesi

\begin{abstract}
Ranked Set Sampling (RSS) is a sampling technique used when the interested variable is difficult to measure with respect to labor, time or cost, but it is possible to rank this variable at a lower cost. In this technique, it is generally preferred that the set size is small to avoid error in the ranking. While statistical inferences are achieved, the information of distribution of the test statistic is needed. Resampling techniques such as bootstrap may be used in cases where distribution information is not available or distribution information cannot be obtained because of the inadequate sample size. In this study, different bootstrap sample selection methods are discussed under RSS. These methods were developed to establish the confidence interval for the difference between two population means. Moreover, with Monte Carlo simulation study, sample selection methods were examined in terms of confidence interval coverage probability and confidence interval widths under some symmetric and skewed distributions. According to the obtained results, the highest confidence interval coverage possibilities were obtained under the standard normal distribution. In addition, for nonsymmetrical distributions, it was found that the confidence interval coverage probabilities increased as the distribution becomes symmetrical. It was observed that the confidence interval coverage probabilities obtained by the method 2 among the proposed methods were higher than the confidence interval coverage probabilities obtained by the method 1 . It was seen that the confidence interval widths became narrow as the variance decreased. In addition, an application study was carried out on obtaining the confidence interval width based on real data.
\end{abstract}

Keywords: Bootstrap, Confidence Interval Coverage Probability, Ranked Set Sampling

\footnotetext{
*a Nurdan Yeniay Koçer, nurdanyeniay@gmail.com, Tel: (312)2021479. orcid.org/0000-0001-8263-1524

${ }^{\mathrm{b}}$ orcid.org/0000-0003-3752-9744 c orcid.org/0000-0002-6310-8727
} 


\section{Giriş}

Sıralı Küme Örneklemesi (SKÖ), özellikle tıp, tarım ve ekoloji gibi alanlarda, ilgilenilen değişkenin ölçümünün emek, maliyet ya da zaman bakımından zor olduğu fakat birimleri ilgili değişken bakımından hassas ölçüm gerektirmeyen bir yöntemle sıralamanın kolay olduğu durumlarda kullanılan bir yöntemdir. SKÖ yöntemi Basit Tesadüfi Örnekleme (BTÖ) yerine kullanılabilecek bir yöntem olarak önerilmiştir (McIntyre, 1952). SKÖ yöntemi ile elde edilecek yığın ortalamasına ait tahmin edicinin yansız ve varyansının BTÖ altındaki örnek ortalaması istatistiğinin varyansından daha küçük olduğu gösterilmiştir (Takahasi ve Wakimoto 1968). Bununla birlikte, sıralama hatası olduğu durumda da, yansızlık ve BTÖ’ye göre etkinlik özelliğinin korunduğunu belirtilmiştir (Dell ve Clutter, 1972). Ayrica, sıralama hataları üzerine çalışmalar da yapılmıştır (David ve Levine, 1972). Bu çalışmaların ardından, görsel yolla siralamalarda, siralama hatasını minimuma indirmek için yardımcı (concomitant) değişkeni kullanarak regresyon tahmin edicisi ele alınmıştır (Stokes, 1977). Aynı zamanda, bu çalışmada SKÖ altında regresyon tahmin edicileri de elde edilmiş̧tir.

İstatistiksel analizlerde hipotez testi ve aralık tahmini gibi çıkarsamalar yapılırken, kullanılan tahmin edicinin dağılım bilgisine ihtiyaç duyulur. Ancak çoğu zaman bu dağılım elde edilemez. Böyle bir durumda genellikle tahmin edicinin varsa asimptotik dağılımı kullanılır. Ancak asimptotik dağılım yaklaşımı örnek çapı yeterince büyük olduğunda güvenilir sonuçlar vermektedir. Emek, zaman, maliyet gibi nedenlerle büyük örnek çapları ile çalışmanın zor olduğu durumlarda küçük örnek çapları ile yeniden örnekleme teknikleri uygulanarak güvenilir sonuçlara ulaşılabilir. Bootstrap yöntemi de bir yeniden örnekleme yöntemidir (Efron, 1979). Bootstrap yönteminde, ilgili tahmin edici, orijinal veri setinden alınan aynı büyüklükte $B$ örnek verisinden hesaplanır. Daha sonra ilgili istatistiğe ilişkin bootstrap dağ 11 m1 oluşturulur. Bootstrap yöntemi güven aralıklarının elde edilmesinde ve hipotez testlerinde yoğun olarak kullanılan bir yöntemdir.

SKÖ yönteminde, birimlerin sıralama hatasını en aza indirmek için genellikle küçük örnek çapları ile çalışılır. Bu durumda, istatistiğe ilişkin dağılım bilgisi elde edilemediğinden, büyük örnek çaplarında güvenilir sonuçlar veren asimptotik yaklaşım yerine, yeniden örnekleme teknikleri tercih edilebilir. Yeniden örnekleme tekniklerinden en sık kullanılanı Bootstrap yöntemidir. SKÖ'de bootstrap yöntemi ilk olarak (Modarres vd., 2006) tarafindan tek grup yığın ortalaması için güven aralığının kapsama olasılıklarının elde edilmesinde kullanılmıştır. Ayrıca uygulamada sık rastlanmayan bir dağılım olan RambergSchmeiser-Tukey (RST) $\lambda$ dağılım ailesini kullanmışlardır. (Yeniay vd., 2017) SKÖ altında bootstrap yöntemini kullanarak, simetrik ve simetrik olmayan farklı dağılımlar altında tek grup yığın ortalaması için hem güven aralığı kapsama olasılıklarını hem de güven aralığı genişliklerini simülasyon yoluyla elde etmişlerdir. (Albatineh vd., 2014), SKÖ altında yığın değişim katsayısı için güven aralığı çalışması gerçekleştirmiştir. Bununla birlikte, (Akgül vd., 2018), SKÖ'de Weibull dağılımı kullanarak sistem güvenilirliği için asimptotik ve bootstrap güven aralıklarını incelemişlerdir. (Mahdizadeh ve Zamanzade, 2018) SKÖ yöntemine dayalı olarak stres dayanıklılık modeli için asimptotik ve yeniden örneklemeye dayalı aralık tahmini çalışması gerçekleştirmişlerdir.

Uygulamadaki çalışmalar genellikle iki grup yığın ortalaması farkına ilişkin güven aralığı kapsama olasılıkları ile ilgilidir. Burada, her grup için ilgili değişkenin ölçümünün zor olduğu durumlarda küçük örnek çapları ile çalışmak gerektiğinden bootstrap yöntemi kullanılarak güven aralığı elde edilebilir.

$\mathrm{Bu}$ çalışmada, SKÖ altında bootstrap yöntemi kullanılarak iki yığın ortalaması farkına ilişkin güven aralığı çalışması gerçekleştirilmiştir. 2. Bölümde SKÖ'de örnek seçim işlemi ve güven aralığı kavramı verilecektir. Bunun yanında, SKÖ altında bootstrap yöntemine dayalı olarak (Modarres vd., 2006) tarafindan önerilen yöntemler iki yığın ortalama farkı için geliştirilmiş olarak verilmiştir. 3. Bölümde simülasyon çalışması sonuçları yer alacaktır. 4. Bölümde, gerçek veriye dayalı uygulama çalışmasına yer verilmiştir. Sonuçlar ise son bölümde özetlenmiştir.

\section{Sıralı Küme Örneklemesinde Örnek Seçim İşlemi ve Güven Aralığı}

Bu bölümde öncelikle SKÖ'de örnek seçim işlemi verilecek ve ardından güven aralığı kavramı tanitılacaktır.

SKÖ'de tek grup için örnek seçim işleminde öncelikle ilgili yığından her biri $m$ büyüklüğünde $m$ örnek BTÖ kullanılarak seçilir ve seçilen bu örnekler 'küme' olarak isimlendirilir. $\mathrm{Bu}$ işlem yığından seçilecek $m^{2}$ örneğin $m$ çaplı $m$ kümeye 
BTÖ ile paylaştırılması ile de gerçekleştirilebilir. Birinci aşamada her bir küme ilgili $Y$ değişkeni bakımından hassas ölçüm gerektirmeyen bir yöntemle ölçülerek küçükten büyüğe sıralanır. Bu sıralama işlemi uzman görüşüyle ya da ilgili değişkenle yüksek derecede ilişkili bir yardımcı değişken bilgisi ile elde edilen düşük düzeyli bir ölçümdür. Daha sonraki aşamada ilk kümeden birinci birim, ikinci kümeden ikinci birim ve bu işlem $m$ küme için yapılarak $m$. kümeden $m$. birim örneğe alınır. Seçilen bu birimler ilgilenilen $Y$ değişkenine göre araştırmanın gerektirdiği hassas bir ölçümle ölçülür. Elde edilen bu $m$ çaplı örnek sıralı küme örneğini oluşturur.

Yukarıda açıklanan örnek seçim işlemi ayrı ayrı iki grup için yapılabilir. Bu durumda 1. ve 2. Grup için küme çapları sırasıyla $m_{1}$ ve $m_{2}$ olmak üzere, $m_{1}=m_{2}=m$ olacak şekilde iki grup için örnek seçim işlemi görsel olarak Tablo 1'de verilmiştir.

Tablo 1. İki grup için sıralı küme örneğinin oluşturulması

\begin{tabular}{|c|c|c|c|c|c|}
\hline \multicolumn{6}{|c|}{ 1. Grup } \\
\hline Küme & Yığından seçilen örnek birimleri & \multirow{5}{*}{$\Rightarrow$} & Sıralanan örnek birimleri & \multirow{5}{*}{$\Rightarrow$} & Örneğe alınan birimler \\
\hline 1 & $Y_{111} Y_{112} \ldots Y_{11 m}$ & & $Y_{1[1] 1} Y_{1[1] 2} \ldots Y_{1[m] 1}$ & & $Y_{1(1)} \quad * \quad \ldots \quad *$ \\
\hline 2 & $Y_{121} Y_{122} \ldots Y_{12 m}$ & & $Y_{1[1] 2} Y_{1[2] 2} \ldots Y_{1[2] 2}$ & & $* Y_{1(2)} \quad \ldots \quad *$ \\
\hline$\vdots$ & $\vdots \quad \vdots \quad \ddots \quad \vdots$ & & $\begin{array}{llll}\vdots & \vdots & \ddots & \vdots\end{array}$ & & $\vdots \quad \vdots \quad \ddots \quad \vdots$ \\
\hline $\mathrm{m}$ & $Y_{1 m 1} Y_{1 m 2} \ldots Y_{1 m m}$ & & $Y_{1[1] m} Y_{1[2] m} \cdots Y_{1[m] m}$ & & $\begin{array}{llll}* & * & \ldots & Y_{1(m)}\end{array}$ \\
\hline \multicolumn{6}{|c|}{ 2. Grup } \\
\hline Küme & Yığından seçilen örnek birimleri & & Sıralanan örnek birimleri & \multirow{5}{*}{$\Rightarrow$} & Örneğe alınan birimler \\
\hline 1 & $Y_{211} Y_{212} \ldots Y_{21 m}$ & & $Y_{2[1] 1} Y_{2[1] 2} \ldots Y_{2[m] 1}$ & & $Y_{1(1)} \quad * \quad \ldots \quad *$ \\
\hline 2 & $Y_{221} Y_{222} \ldots Y_{22 m}$ & $\Rightarrow$ & $Y_{2[1] 2} Y_{2[2] 2} \ldots Y_{2[2] 2}$ & & $* Y_{1(2)}$ \\
\hline$\vdots$ & $\begin{array}{llll}\vdots & \vdots & \ddots & \vdots\end{array}$ & & $\begin{array}{llll}\vdots & \vdots & \ddots & \vdots\end{array}$ & & $\vdots \quad \vdots \quad \ddots \quad \quad \vdots$ \\
\hline $\mathrm{m}$ & $Y_{2 m 1} Y_{2 m 2} \ldots Y_{2 m m}$ & & $Y_{2[1] m} Y_{2[2] m} \cdots Y_{2[m] m}$ & & $\begin{array}{llll}* & * & \ldots & Y_{1(m)}\end{array}$ \\
\hline
\end{tabular}

Burada, $i=1,2, \ldots, m$ ve $k=1,2$ olmak üzere, $\left\{Y_{k i 1}, Y_{k i 2}, \ldots, Y_{k i m}\right\} k$. gruptan BTÖ ile seçilen aynı $F(y)$ dağılım fonksiyonuna sahip örnek birimlerini, $\left\{Y_{k[i] 1}, Y_{k[i] 2}, \ldots, Y_{k[i] m}\right\} k$. gruptan $i$. küme için hassas olmayan bir ölçümle küçükten büyüğe sıralanmış birimleri ve $\left\{Y_{k(i)}, i=1,2, \ldots m\right\}$ sıralamada hata yapılmadığ grup için $i$. kümeden hassas ölçüm yapılarak alınan $i$. sıradaki örnek birimini gösterir. Yukarıda açıklanan örnek seçim işlemleri her bir grup için $r_{1}$ ve $r_{2}$ kez tekrarlanabilir. $r_{1}$ ve $r_{2}$ döngü sayılarını

Tablo 2. İki grup için $n_{1}$ ve $n_{2}$ çaplı sıralı küme örnekleri

\begin{tabular}{|c|c|c|c|c|}
\hline \multicolumn{5}{|c|}{ 1. Grup } \\
\hline \multirow{2}{*}{ Küme } & \multicolumn{4}{|c|}{ Döngü } \\
\hline & \multicolumn{3}{|c|}{$2 \quad \ldots$} & $r_{1}$ \\
\hline 1 & $Y_{1(1) 1}$ & $Y_{1(1) 2}$ & $\ldots$ & $Y_{1(1) r_{1}}$ \\
\hline 2 & $Y_{1(2) 1}$ & $Y_{1(2) 2}$ & $\ldots$ & $Y_{1(2) r_{1}}$ \\
\hline$\vdots$ & $\vdots$ & $\vdots$ & $\vdots$ & $\vdots$ \\
\hline$m$ & $Y_{1(m) 1}$ & $Y_{1(m) 2}$ & $\ldots$ & $Y_{1(m) r_{1}}$ \\
\hline \multicolumn{5}{|c|}{ 2. Grup } \\
\hline \multirow{2}{*}{ Küme } & \multicolumn{4}{|c|}{ Döngü } \\
\hline & 1 & 2 & $\ldots$ & $r_{2}$ \\
\hline 1 & $Y_{2(1) 1}$ & $Y_{2(1) 2}$ & $\ldots$ & $Y_{2(1) r_{1}}$ \\
\hline 2 & $Y_{2(2) 1}$ & $Y_{2(2) 2}$ & $\ldots$ & $Y_{2(2) r_{1}}$ \\
\hline$\vdots$ & $\vdots$ & $\vdots$ & $\vdots$ & $\vdots$ \\
\hline$m$ & $Y_{2(m) 1}$ & $Y_{2(m) 2}$ & $\ldots$ & $Y_{2(m) r_{1}}$ \\
\hline
\end{tabular}

göstermek üzere; $r_{1}$ ve $r_{2}$ döngü sonunda $n_{1}=m r_{1}$ ve $n_{2}=m r_{2}$ çaplı sıralı küme örnekleri elde edilecektir. Bu örnekler Tablo 2'de verildiği gibidir.

Burada $\quad Y_{k(i) j}, k=1,2 ; i=1,2, \ldots, m ; j=$ $1,2, \ldots r_{k}$ olmak üzere; $k$. grup için $j$. döngüdeki $i$. sıra istatistiğidir. $\mathrm{Bu}$ istatistik kullanılarak, $k$. grubun yığın ortalaması için tahmin edici

$\bar{Y}_{k(S K O ̈)}=\frac{1}{m r_{k}} \sum_{i=1}^{m} \sum_{j=1}^{r_{k}} Y_{k(i) j}, k=1,2$

şeklinde tanımlanır.

$\mathrm{Bu}$ tahmin edicinin beklenen değeri

$E\left(\bar{Y}_{k(\text { SKÖ })}\right)=\mu_{k} \quad, \quad k=1,2$

olacaktır.

Eş(1) de verilen tahmin edicin varyansı ise

$\operatorname{Var}\left(\bar{Y}_{k(S K \ddot{O})}\right)=\frac{\sigma_{k}^{2}}{m r_{k}}-\frac{1}{m^{2} r_{k}} \sum_{i=1}^{m}\left(\mu_{i: m}-\mu_{k}\right)$

(3)

şeklinde tanımlanır. Burada $\mu_{i: m}$; herhangi bir grup için $m$ çaplı örnekteki $i$. sıra istatistiğ ortalamasıdır. Ayrıca $\mu_{k}, k$. grup yığın ortalamasını ve $\sigma_{k}^{2}$ ise $k$. grubun varyansinı ifade eder.

Uygulamada, sıralı küme örneği oluşturulurken, görsel yolla sıralama gibi kişisel bir sıralama 
yöntemi kullanıldığında, sıralamada hatanın minimum düzeyde tutulabilmesi için küme çapının 5 'ten küçük olması tercih edilir (Patil vd., 1997).

SKÖ ile elde edilen örneklerden hipotez testi veya aralık tahmini yapılabilmesi için Eş(1)'de verilen tahmin edicinin dağılımına ihtiyaç duyulur. Fakat uygulamada çoğu zaman bu dağ 1 lım elde edilemez. $\mathrm{Bu}$ durumda asimptotik yöntemleri kullanmak gerekir. Ancak, asimptotik yöntemlerin büyük örnek çaplarında daha güvenilir sonuçlar vermesinden dolay1, SKÖ gibi küçük örnek çaplarının kullanıldığ 1 durumlarda bootstrap gibi yeniden örnekleme tekniklerine başvurulur.

(Modarres vd., 2006) tarafindan önerilen algoritmalardan yararlanarak iki grup için geliştirilen bootstrap örnek seçim yöntemleri aşağıda detaylı olarak yer almıştır.

Örnek seçim yöntemlerinde $Y_{1(i) j}$ ve $Y_{2(i) j}$ sıralı küme örnekleri Tablo 2'de verilmiştir. Bootstrap sıralı küme örnekleri, bu sıralı küme örneklerinin her biri içinden örnek seçim işlemi gerçekleştirilerek oluşturulacaktır. Bununla birlikte seçilen bootstrap örnekleri $Y_{1(i) j}^{*}$ ve $Y_{2(i) j}^{*}$ ile gösterilecektir.

\section{Yöntem}

1) $Y_{1(i) 1}^{*}, Y_{1(i) 2}^{*}, \ldots, Y_{1(i) r_{1}}^{*}$ ve

$Y_{2(i) 1}^{*}, Y_{2(i) 2}^{*}, \ldots, Y_{2(i) r_{2}}^{*}$ bootstrap siralı küme örneklerini oluşturmak için Tablo 2'de verilen iki sıralı küme örneğinin her birinin $i$. satırından $(i=1,2, \ldots, m)$ rastgele yerine koyarak $\frac{1}{r_{1}}$ olasilıkla $r_{1}$ birim 1. Bootstrap sıralı küme örneği için, $\frac{1}{r_{2}}$ olasılıkla $r_{2}$ birim 2. Bootstrap siralı küme örneği için seçilir.

2) Adım 1, $Y_{1(i) j}^{*}$ ve $Y_{2(i) j}^{*}$ bootstrap sıralı küme örneklerini elde etmek üzere, her bir grup ve her bir $i$ satır için $m$ kez tekrarlanır.

\section{Yöntem}

1) Tablo 2'de verilen iki sıralı küme örneğinde yer alan birimlere $\frac{1}{m r_{1}}$ ve $\frac{1}{m r_{2}}$ olasılığ 1 atanır ve 1 . grup için rastgele yerine koyarak $m$ birim seçilir. Bu birimler $x_{1}, x_{2}, \ldots, x_{m} \sim F_{n}$ şeklinde dağılmak üzere, $\quad x_{(1)} \leq x_{(2)} \leq \cdots \leq x_{(m)}$ biçiminde sıralanır. Böylece $Y_{1(i) j}^{*}=x_{j}$ elde edilmiş olur. Ardından 2. grup için rastgele yerine koyarak $m$ birim daha seçilir. Benzer şekilde, $s_{1}, s_{2}, \ldots, s_{m} \sim$ $G_{n}$ şeklinde dağılmak üzere, $s_{(1)} \leq s_{2} \leq \cdots \leq$ $s_{(m)}$ biçiminde sıralanır. Böylece $Y_{2(i) j}^{*}=s_{i}$ elde edilir.

2) Adım 1, her grup için $m$ defa tekrarlanır.

3) Her iki Adım, $Y_{1(i) j}^{*}$ ve $Y_{2(i) j}^{*}$ elde etmek için $r_{1}$ ve $r_{2}$ defa tekrar edilir.

Bu çalışmada SKÖ altında bootstrap yöntemi ile güven aralığı kapsama olasılıkları elde edilirken bootstrap yüzdeliklerine dayalı güven aralığı yöntemi kullanılmıştır. Bu yöntem ile elde edilen güven aralıkları için kullanılan algoritma aşağıda verildiğgi gibidir.

1) Yukarıda verilen her bir yöntem ile elde edilen bootstrap sıralı küme örnekleri $Y_{1(i) j}^{*}$ ve $Y_{2(i) j}^{*}$ ile gösterilmek üzere, her bir bootstrap örneğinden $\bar{Y}_{1(S K O ̈)}^{*}$ ve $\bar{Y}_{2(S K O ̈)}^{*}$ değerleri aşağıdaki eşitlik yardımıyla elde edilir.

$\bar{Y}_{k(S K O ̈)}^{*}=\frac{1}{m r_{k}} \sum_{i=1}^{m} \sum_{j=1}^{r_{k}} Y_{k(i) j}^{*}, k=1,2$.

2) Ardından her bir bootstap örneği için ilgilenilen istatistik $\bar{Y}_{1(i) j}^{*}-\bar{Y}_{2(i) j}^{*}$ elde edilir.

3) Toplam bootstrap örnek sayısı $B$ olmak üzere elde edilen tüm $\bar{Y}_{1(i) j}^{*}-\bar{Y}_{2(i) j}^{*}$ istatistikleri küçükten büyüğe sıralanır.

$$
\begin{aligned}
\left(\bar{Y}_{1(i) j}^{*}-\bar{Y}_{2(i) j}^{*}\right)_{(1)} & \leq\left(\bar{Y}_{1(i) j}^{*}-\bar{Y}_{2(i) j}^{*}\right)_{(2)} \leq \cdots \\
\leq & \left(\bar{Y}_{1(i) j}^{*}-\bar{Y}_{2(i) j}^{*}\right)_{(B)}
\end{aligned}
$$

4) $l=\frac{\alpha \beta}{2}$ ve $u=B-l$ değerleri elde edilir.

5) $\% 100(1-\alpha)$ güven düzeyindeki güven aralığı, sıralanmış verinin $(l+l)$. sıradaki ve $u$. siradaki $\left(\bar{Y}_{1(i) j}^{*}-\bar{Y}_{2(i) j}^{*}\right)$ değerleri ile elde edilir. $\mathrm{Bu}$ değerler güven aralığının alt ve üst sınırlarını oluşturacaktır.

SKÖ altında yukarıda açıklanan bootstrap yöntemleri ile elde edilen örnekler kullanılarak, iki yığın ortalama farkına ilişkin güven aralığı kapsama olasılığı ve genişliklerini incelemek amacıyla simülasyon çalışması yapılmıştır. Bir sonraki bölümde simülasyon çalışması yer alacaktır.

\section{Simülasyon Çalış̧ması}

SKÖ altında bootstrap yöntemi kullanımı ilk olarak (Modarres vd., 2006) tarafindan gerçekleştirilmiştir. $\mathrm{Bu}$ çalışmada RambergSchmeiser-Tukey (RST) $\lambda$ dağılım ailesinden 4 tane simetrik 4 tane de çarpık dağglım ele alınmış ve tek grup yığın ortalamasına ilişkin güven aralığı 
kapsama olasılı̆̆ çalışması gerçekleştirilmiştir. Kullanılan bu dağılım ailesi uygulamada çok sık rastlanan bir dağılım ailesi olmadığından bu çalışmada uygulamada daha sık olarak kullanılan tek modlu simetrik dağılımlardan Standart Normal $(0,1)$, çok modlu simetrik bir dağılım olan Uniform $(0,1)$ ve simetrik olmayan dağ 1 lımlardan Gamma $(0.5,1)$, Gamma $(4,1)$, Invers Gauss (1, 1.13), Invers Gauss (1, 9.09) dağılımları kullanılmıştır. Kullanılan simetrik olmayan dağılımlarda parametreler, aynı çarpıklık değerini verecek şekilde düzenlenmiştir. Bu durumda Gamma (0.5, 1) ile Invers Gauss $(1,1.13)$ dağılımları ve Gamma $(4,1)$ ile Invers Gauss $(1,9.09)$ dağılımları aynı çarpıklık değerlerini vermektedir. SKÖ'de sıralama hatasını en aza indirmek için küme çapının genellikle küçük olması istenir. Bu nedenle SKÖ ile seçilecek örnekler için küme büyüklükleri $m=2,3,4,5,6$ alınmıştır. Ayrıca gerekli örnek çapını sağlamak için döngü sayıları küçükten büyüğe $r_{1}=$ $r_{2}=2,4,6,8$ ve 10 olarak alınmıştır. Farklı durumlarda genel tekrar sayısı denenmiştir ve genel tekrar $\mathrm{T}=5000$ olacak şekilde simülasyon çalışması düzenlenmiştir. Bootstrap tekrar sayısı
B=2000 alınmıştır. İki yığın ortalaması farkına ilişkin güven aralığ 1 simülasyon çalışmasında güven düzeyi $\% 95$ olarak alınmıştır. Güven aralığ1 genişlikleri (GA genişliği), tüm mümkün Bootstrap örnekleri üzerinden güven aralığı alt ve üst sınırları arasındaki fark alınarak ortalama güven aralığı genişliği elde edilmiştir. Güven aralı̆̆ kapsama olasılığı (GA oranı) ise 2. Bölümde açıklanan algoritma yardımıyla elde edilmiştir. Simülasyon çalışması MATLAB R2007b programı yardımıyla yapılmıştır. Sonuçlar Tablo 3-8'de verilmiştir.

Tablo 3, standart normal dağglım için güven aralığı kapsama olasılıklarını ve genişliklerini vermektedir. Tablo 3'e göre; incelenen tüm küme çapları için 2. yöntem ile elde edilen GA oranları 1. yöntem ile elde edilen GA oranlarından daha yüksektir. Bununla birlikte elde edilen GA genişlikleri incelendiğinde, küme çap $m=2$ için 2 . yöntemle elde edilen genişlikler daha yüksek iken küme çap1 arttıkça 1. yöntemle elde edilen GA genişlikleri daha yüksek olmaktadır. Ayrıca aynı döngü sayıları için küme çapı arttıkça GA oranları artmakta ve GA genişlikleri azalmaktadır.

Tablo 3: Standart Normal dağılım altında iki yığın ortalamasına ilişkin güven aralığı kapsama olasılığı ve güven aralığ̀ geniş̧likleri

\begin{tabular}{|c|c|c|c|c|c|}
\hline \multirow{2}{*}{ Küme çapı } & \multirow{2}{*}{$\begin{array}{l}\text { Döngü } \\
r_{1}=r_{2}\end{array}$} & \multicolumn{2}{|c|}{ 1. Yöntem } & \multicolumn{2}{|c|}{ 2. Yöntem } \\
\hline & & GA oranı & GA genişliği & GA oranı & GA genişliği \\
\hline \multirow{5}{*}{$m=2$} & 2 & 0.7384 & 1.4612 & 0.8906 & 2.0490 \\
\hline & 4 & 0.8864 & 1.3623 & 0.9252 & 1.5360 \\
\hline & 6 & 0.9124 & 1.1862 & 0.9345 & 1.3662 \\
\hline & 8 & 0.9258 & 1.0302 & 0.9424 & 1.1192 \\
\hline & 10 & 0.9216 & 0.9633 & 0.9428 & 1.0091 \\
\hline \multirow{5}{*}{$m=3$} & 2 & 0.7650 & 1.0840 & 0.9375 & 1.0015 \\
\hline & 4 & 0.8984 & 0.9831 & 0.9415 & 0.9716 \\
\hline & 6 & 0.9162 & 0.8567 & 0.9475 & 0.8455 \\
\hline & 8 & 0.9268 & 0.7574 & 0.9480 & 0.7452 \\
\hline & 10 & 0.9338 & 0.6913 & 0.9500 & 0.6854 \\
\hline \multirow{5}{*}{$m=4$} & 2 & 0.8020 & 0.9190 & 0.9355 & 0.8783 \\
\hline & 4 & 0.8310 & 0.8779 & 0.9380 & 0.6347 \\
\hline & 6 & 0.9154 & 0.6350 & 0.9460 & 0.5119 \\
\hline & 8 & 0.9264 & 0.5133 & 0.9500 & 0.4501 \\
\hline & 10 & 0.9324 & 0.4498 & 0.9505 & 0.3992 \\
\hline \multirow{5}{*}{$m=5$} & 2 & 0.7950 & 0.7177 & 0.9360 & 0.7278 \\
\hline & 4 & 0.8930 & 0.6359 & 0.9410 & 0.5168 \\
\hline & 6 & 0.9184 & 0.5525 & 0.9470 & 0.4252 \\
\hline & 8 & 0.9272 & 0.4906 & 0.9485 & 0.3682 \\
\hline & 10 & 0.9336 & 0.4451 & 0.9505 & 0.3315 \\
\hline \multirow{5}{*}{$m=6$} & 2 & 0.8118 & 0.6131 & 0.9375 & 0.6315 \\
\hline & 4 & 0.9040 & 0.5439 & 0.9465 & 0.4436 \\
\hline & 6 & 0.9242 & 0.4703 & 0.9485 & 0.3630 \\
\hline & 8 & 0.9338 & 0.4183 & 0.9490 & 0.3148 \\
\hline & 10 & 0.9386 & 0.3790 & 0.9565 & 0.2823 \\
\hline
\end{tabular}


Tablo 4: Uniform $(0,1)$ dağılım altında iki yığın ortalamasına ilişkin güven aralığı kapsama olasılığı ve güven aralığı genişlikleri

\begin{tabular}{|c|c|c|c|c|c|}
\hline \multirow{2}{*}{ Küme çapı } & \multirow{2}{*}{$\begin{array}{l}\text { Döngü } \\
r_{1}=r_{2}\end{array}$} & \multicolumn{2}{|c|}{ 1. Yöntem } & \multicolumn{2}{|c|}{ 2. Yöntem } \\
\hline & & GA oranı & GA genişliği & GA oranı & GA genişliği \\
\hline \multirow{5}{*}{$m=2$} & 2 & 0.7482 & 0.4191 & 0.8882 & 0.5991 \\
\hline & 4 & 0.8858 & 0.3914 & 0.9268 & 0.4478 \\
\hline & 6 & 0.9148 & 0.3401 & 0.9416 & 0.3700 \\
\hline & 8 & 0.9254 & 0.3030 & 0.9404 & 0.3217 \\
\hline & 10 & 0.9360 & 0.2756 & 0.9418 & 0.2890 \\
\hline \multirow{5}{*}{$m=3$} & 2 & 0.7680 & 0.3097 & 0.9382 & 0.3450 \\
\hline & 4 & 0.8946 & 0.2782 & 0.9424 & 0.2890 \\
\hline & 6 & 0.9212 & 0.2413 & 0.9440 & 0.2661 \\
\hline & 8 & 0.9224 & 0.2146 & 0.9532 & 0.2308 \\
\hline & 10 & 0.9300 & 0.1956 & 0.9416 & 0.2066 \\
\hline \multirow{5}{*}{$m=4$} & 2 & 0.7918 & 0.2423 & 0.9458 & 0.3645 \\
\hline & 4 & 0.8964 & 0.2162 & 0.9468 & 0.2556 \\
\hline & 6 & 0.9146 & 0.1573 & 0.9482 & 0.2084 \\
\hline & 8 & 0.9252 & 0.1666 & 0.9492 & 0.1800 \\
\hline & 10 & 0.9336 & 0.1513 & 0.9516 & 0.1608 \\
\hline \multirow{5}{*}{$m=5$} & 2 & 0.7978 & 0.1996 & 0.9445 & 0.3195 \\
\hline & 4 & 0.9046 & 0.1773 & 0.9496 & 0.2095 \\
\hline & 6 & 0.9196 & 0.1530 & 0.9480 & 0.1705 \\
\hline & 8 & 0.9342 & 0.1362 & 0.9450 & 0.1380 \\
\hline & 10 & 0.9356 & 0.1235 & 0.9495 & 0.1250 \\
\hline \multirow{5}{*}{$m=6$} & 2 & 0.8022 & 0.1692 & 0.9466 & 0.2005 \\
\hline & 4 & 0.9048 & 0.1495 & 0.9480 & 0.1550 \\
\hline & 6 & 0.9166 & 0.1294 & 0.9500 & 0.1442 \\
\hline & 8 & 0.9302 & 0.1152 & 0.9500 & 0.1250 \\
\hline & 10 & 0.9294 & 0.1044 & 0.9505 & 0.1060 \\
\hline
\end{tabular}

Tablo 4, Uniform dağılım altında elde edilen sonuçları vermektedir. Tablo 4'e göre, incelenen tüm küme çapları için 2.yönteme göre elde edilen GA oranları 1. yöntem ile elde edilen GA oranlarından yüksektir. Ancak GA genişliği bakımından inceleme yapıldığında, 1. yöntemle elde edilen GA genişlikleri daha küçüktür.

Tablo 5. Gamma $(0.5,1)$ dağılım altında iki yığın ortalamasına ilişkin güven aralığı kapsama olasılığı ve güven aralığ genişlikleri

\begin{tabular}{|c|c|c|c|c|c|}
\hline \multirow{2}{*}{ Küme çapı } & \multirow{2}{*}{$\begin{array}{l}\text { Döngü } \\
r_{1}=r_{2}\end{array}$} & \multicolumn{2}{|c|}{ 1. Yöntem } & \multicolumn{2}{|c|}{ 2. Yöntem } \\
\hline & & GA oranı & GA genişliği & GA oranı & GA genişliği \\
\hline \multirow{5}{*}{$m=2$} & 2 & 0.7082 & 0.9420 & 0.8668 & 1.2748 \\
\hline & 4 & 0.8578 & 0.9678 & 0.8972 & 1.0504 \\
\hline & 6 & 0.8944 & 0.8565 & 0.9078 & 0.9047 \\
\hline & 8 & 0.9124 & 0.7804 & 0.9190 & 0.8005 \\
\hline & 10 & 0.9134 & 0.7062 & 0.9292 & 0.7239 \\
\hline \multirow{5}{*}{$m=3$} & 2 & 0.7308 & 0.7518 & 0.8962 & 1.0598 \\
\hline & 4 & 0.8748 & 0.7448 & 0.9034 & 0.8257 \\
\hline & 6 & 0.8952 & 0.6595 & 0.9172 & 0.6979 \\
\hline & 8 & 0.9150 & 0.5921 & 0.9322 & 0.6209 \\
\hline & 10 & 0.9150 & 0.5427 & 0.9280 & 0.5614 \\
\hline \multirow{5}{*}{$m=4$} & 2 & 0.7422 & 0.6296 & 0.9100 & 0.8985 \\
\hline & 4 & 0.8734 & 0.6064 & 0.9196 & 0.6860 \\
\hline & 6 & 0.8986 & 0.5381 & 0.9318 & 0.5775 \\
\hline & 8 & 0.9092 & 0.4802 & 0.9350 & 0.5067 \\
\hline & 10 & 0.9200 & 0.4397 & 0.9320 & 0.4559 \\
\hline \multirow{5}{*}{$m=5$} & 2 & 0.7508 & 0.5538 & 0.9142 & 0.7849 \\
\hline & 4 & 0.8752 & 0.5185 & 0.9296 & 0.5844 \\
\hline & 6 & 0.9042 & 0.4577 & 0.9304 & 0.4918 \\
\hline & 8 & 0.9110 & 0.4074 & 0.9290 & 0.4342 \\
\hline & 10 & 0.9236 & 0.3745 & 0.9390 & 0.3880 \\
\hline \multirow{5}{*}{$m=6$} & 2 & 0.7542 & 0.4836 & 0.9058 & 0.6889 \\
\hline & 4 & 0.8862 & 0.4562 & 0.9154 & 0.5180 \\
\hline & 6 & 0.8980 & 0.3969 & 0.9220 & 0.8990 \\
\hline & 8 & 0.9154 & 0.3577 & 0.9224 & 0.8024 \\
\hline & 10 & 0.9220 & 0.3263 & 0.9322 & 0.7324 \\
\hline
\end{tabular}


Tablo 5 'te verilen Gamma $(0.5,1)$ dağılımı altında elde edilen sonuçlar incelendiğinde ise; 2. yöntemle elde edilen GA oranlarının 1. yöntem ile elde edilen GA oranlarından daha yüksek olduğu görülmektedir. Ancak elde edilen GA genişlikleri incelendiğinde, 1. yöntemin daha dar GA genişliği verdiği görülmektedir.

Tablo 6. Gamma (4,1) dağılım altında iki yığın ortalamasına ilişkin güven aralığı kapsama olasılığı ve güven aralığı genişlikleri

\begin{tabular}{|c|c|c|c|c|c|}
\hline \multirow{2}{*}{ Küme çapı } & \multirow{2}{*}{$\begin{array}{c}\text { Döngü } \\
r_{1}=r_{2}\end{array}$} & \multicolumn{2}{|c|}{ 1. Yöntem } & \multicolumn{2}{|c|}{ 2. Yöntem } \\
\hline & & GA oranı & GA genişliği & GA oranı & GA genişliği \\
\hline \multirow{5}{*}{$m=2$} & 2 & 0.7430 & 2.8903 & 0.8786 & 4.0258 \\
\hline & 4 & 0.8802 & 2.7433 & 0.9176 & 3.0629 \\
\hline & 6 & 0.9070 & 2.3807 & 0.9276 & 2.5589 \\
\hline & 8 & 0.9120 & 2.1362 & 0.9328 & 2.2363 \\
\hline & 10 & 0.9296 & 1.9404 & 0.9360 & 2.0169 \\
\hline \multirow{5}{*}{$m=3$} & 2 & 0.7704 & 2.1704 & 0.9200 & 3.1031 \\
\hline & 4 & 0.8874 & 2.0022 & 0.9314 & 2.2806 \\
\hline & 6 & 0.9094 & 1.7339 & 0.9372 & 1.8853 \\
\hline & 8 & 0.9188 & 1.5441 & 0.9398 & 1.6460 \\
\hline & 10 & 0.9318 & 1.4051 & 0.9382 & 1.4690 \\
\hline \multirow{5}{*}{$m=4$} & 2 & 0.7820 & 1.7573 & 0.9288 & 2.5237 \\
\hline & 4 & 0.8930 & 1.5801 & 0.9420 & 1.8256 \\
\hline & 6 & 0.9174 & 1.3667 & 0.9446 & 1.5016 \\
\hline & 8 & 0.9292 & 1.2250 & 0.9452 & 1.3017 \\
\hline & 10 & 0.9338 & 1.1112 & 0.9428 & 1.1679 \\
\hline \multirow{5}{*}{$m=5$} & 2 & 0.7814 & 1.4532 & 0.9346 & 2.1264 \\
\hline & 4 & 0.8962 & 1.3134 & 0.9460 & 1.5146 \\
\hline & 6 & 0.9194 & 1.1339 & 0.9408 & 1.2468 \\
\hline & 8 & 0.9188 & 1.0120 & 0.9464 & 1.0844 \\
\hline & 10 & 0.9306 & 0.9180 & 0.9498 & 0.9696 \\
\hline \multirow{5}{*}{$m=6$} & 2 & 0.7912 & 1.2498 & 0.9300 & 1.8412 \\
\hline & 4 & 0.8846 & 1.1268 & 0.9328 & 1.3079 \\
\hline & 6 & 0.9142 & 0.9740 & 0.9436 & 1.1679 \\
\hline & 8 & 0.9280 & 0.8660 & 0.9442 & 1.0738 \\
\hline & 10 & 0.9308 & 0.7866 & 0.9494 & 0.9287 \\
\hline
\end{tabular}

Tablo 6'da Gamma $(4,1)$ dağılımı kullanılarak elde edilen sonuçlar yer almaktadır. Tablo 6 incelendiğinde, 2. yöntemle elde edilen GA oranlarının daha yüksek olduğu ancak GA genişliği bakımından incelendiğinde 1. yöntemle elde edilen GA genişliklerinin 2. yöntemle elde edilen GA genişliklerinden daha düşük olduğu görülmektedir. 
Tablo 7. Invers Gauss $(1,1.13)$ dağılım altında iki yığın ortalamasına ilişkin güven aralığı kapsama olasılığı ve güven aralığı genişlikleri

\begin{tabular}{|c|c|c|c|c|c|}
\hline \multirow{2}{*}{ Küme çapı } & \multirow{2}{*}{$\begin{array}{c}\text { Döngü } \\
r_{1}=r_{2}\end{array}$} & \multicolumn{2}{|c|}{ 1. Yöntem } & \multicolumn{2}{|c|}{ 2. Yöntem } \\
\hline & & GA oranı & GA genişliği & GA oranı & GA genişliği \\
\hline \multirow{5}{*}{$m=2$} & 2 & 0.7266 & 1.2658 & 0.8280 & 1.7141 \\
\hline & 4 & 0.8628 & 1.2613 & 0.9040 & 1.3759 \\
\hline & 6 & 0.8930 & 1.1305 & 0.9090 & 1.1876 \\
\hline & 8 & 0.9100 & 1.0226 & 0.9210 & 1.0630 \\
\hline & 10 & 0.9150 & 0.9401 & 0.9240 & 0.9631 \\
\hline \multirow{5}{*}{$m=3$} & 2 & 0.7446 & 1.0011 & 0.8840 & 1.4120 \\
\hline & 4 & 0.8754 & 0.9675 & 0.9160 & 1.0833 \\
\hline & 6 & 0.8936 & 0.8539 & 0.9230 & 0.9170 \\
\hline & 8 & 0.9154 & 0.7449 & 0.9260 & 0.8096 \\
\hline & 10 & 0.9230 & 0.6832 & 0.9340 & 0.7323 \\
\hline \multirow{5}{*}{$m=4$} & 2 & 0.7624 & 0.8431 & 0.9030 & 1.1819 \\
\hline & 4 & 0.8740 & 0.7956 & 0.9210 & 0.9008 \\
\hline & 6 & 0.9080 & 0.6975 & 0.9220 & 0.7537 \\
\hline & 8 & 0.9142 & 0.6295 & 0.9330 & 0.6638 \\
\hline & 10 & 0.9174 & 0.5758 & 0.9340 & 0.5968 \\
\hline \multirow{5}{*}{$m=5$} & 2 & 0.7550 & 0.7245 & 0.9200 & 1.0339 \\
\hline & 4 & 0.8790 & 0.6809 & 0.9220 & 0.7653 \\
\hline & 6 & 0.9086 & 0.5962 & 0.9300 & 0.6415 \\
\hline & 8 & 0.9212 & 0.5359 & 0.9332 & 0.5665 \\
\hline & 10 & 0.9218 & 0.4872 & 0.9342 & 0.5105 \\
\hline \multirow{5}{*}{$m=6$} & 2 & 0.7710 & 0.6365 & 0.9164 & 0.9053 \\
\hline & 4 & 0.8794 & 0.5947 & 0.9300 & 0.6745 \\
\hline & 6 & 0.9122 & 0.5197 & 0.9320 & 0.5642 \\
\hline & 8 & 0.9180 & 0.4664 & 0.9360 & 0.4940 \\
\hline & 10 & 0.9262 & 0.4277 & 0.9417 & 0.4460 \\
\hline
\end{tabular}

Tablo 7, Invers Gauss (1, 1.13) dağılımı altında elde edilen simülasyon sonuçlarını vermektedir. Tablo 7 incelendiğinde, 2. yöntemle elde edilen GA oranlarının 1. yöntem ile elde edilen sonuçlardan daha yüksek olduğu görülmektedir. Bunun yanında, 1. yöntemle elde edilen GA genişliklerinin 2. yöntemle elde edilen GA genişliklerinden daha dar olduğu görülmektedir. 
Tablo 8. Invers Gauss $(1,9.09)$ dağılım altında iki yığın ortalamasına ilişkin güven aralığı kapsama olasılığı ve güven aralığı genişlikleri

\begin{tabular}{|c|c|c|c|c|c|}
\hline \multirow{2}{*}{ Küme çapı } & \multirow{2}{*}{$\begin{array}{c}\text { Döngü } \\
r_{1}=r_{2}\end{array}$} & \multicolumn{2}{|c|}{ 1. Yöntem } & \multicolumn{2}{|c|}{ 2. Yöntem } \\
\hline & & GA oranı & GA genişliği & GA oranı & GA genişliği \\
\hline \multirow{5}{*}{$m=2$} & 2 & 0.7385 & 0.4809 & 0.8764 & 0.6699 \\
\hline & 4 & 0.8692 & 0.4547 & 0.9054 & 0.5079 \\
\hline & 6 & 0.9086 & 0.3962 & 0.9096 & 0.4223 \\
\hline & 8 & 0.9196 & 0.3538 & 0.9242 & 0.3712 \\
\hline & 10 & 0.9220 & 0.3225 & 0.9320 & 0.3344 \\
\hline \multirow{5}{*}{$m=3$} & 2 & 0.7840 & 0.3606 & 0.9024 & 0.3494 \\
\hline & 4 & 0.8922 & 0.3302 & 0.9188 & 0.2591 \\
\hline & 6 & 0.9066 & 0.2884 & 0.9262 & 0.2175 \\
\hline & 8 & 0.9198 & 0.2561 & 0.9286 & 0.1555 \\
\hline & 10 & 0.9272 & 0.2340 & 0.9348 & 0.1409 \\
\hline \multirow{5}{*}{$m=4$} & 2 & 0.7826 & 0.2910 & 0.9124 & 0.2869 \\
\hline & 4 & 0.8838 & 0.2621 & 0.9268 & 0.2094 \\
\hline & 6 & 0.9140 & 0.1699 & 0.9332 & 0.1647 \\
\hline & 8 & 0.9258 & 0.2030 & 0.9340 & 0.1513 \\
\hline & 10 & 0.9274 & 0.1846 & 0.9387 & 0.1365 \\
\hline \multirow{5}{*}{$m=5$} & 2 & 0.7740 & 0.2415 & 0.9240 & 0.2404 \\
\hline & 4 & 0.8918 & 0.2178 & 0.9304 & 0.2010 \\
\hline & 6 & 0.9040 & 0.1887 & 0.9328 & 0.1776 \\
\hline & 8 & 0.9228 & 0.1683 & 0.9360 & 0.1448 \\
\hline & 10 & 0.9286 & 0.1531 & 0.9390 & 0.1261 \\
\hline \multirow{5}{*}{$m=6$} & 2 & 0.7929 & 0.2080 & 0.9190 & 0.2010 \\
\hline & 4 & 0.8962 & 0.1866 & 0.9302 & 0.1650 \\
\hline & 6 & 0.9084 & 0.1610 & 0.9352 & 0.1509 \\
\hline & 8 & 0.9278 & 0.1438 & 0.9362 & 0.1229 \\
\hline & 10 & 0.9345 & 0.1314 & 0.9470 & 0.1071 \\
\hline
\end{tabular}

Tablo 8'de, Invers Gauss $(1,9.09)$ dağılımı altında elde edilen simülasyon sonuçlarını yer almaktadır. Tablo 8 incelendiğinde, 2. yöntemle elde edilen GA oranlarının 1. yöntem ile elde edilen sonuçlardan yüksek olduğu görülmektedir. Bunun yanında, küme çapı $m=2$ iken, 1. yöntemle elde edilen GA genişliklerinin 2. yöntemle elde edilen genişliklerden daha dar olduğu ancak küme çapı ve döngü sayısı artıkça 2. yöntemle elde edilen GA genişliklerinin 1. yöntemle elde edilen genişliklerden daha dar olduğu görülmektedir.

İncelenen tüm dağılımlar GA genişlikleri bakımından birlikte değerlendirildiğinde, aynı çarpıklığa sahip dağılımların farklı GA genişliklerine sahip oldukları gözlenmiştir. Bunun üzerine varyansları bakımından dağılımlar tekrar ele alındığında, aynı küme çapı ve döngü sayısı için değerlendirildiğinde, varyansı en yüksek olan Gamma $(4,1)$ dağılımı için elde edilen GA genişliklerinin en yüksek olduğu belirlenmiştir. Varyans azaldıkça GA genişlikleri de azalmaktadır. Örneğin incelenen dağılımlardan en düşük varyansa sahip olan Uniform $(0,1)$ dağ 11 ımı için elde edilen GA genişlikleri diğer dağılımlar ile elde edilen genişliklerden daha dardır.

\section{Uygulama}

Bu bölümde, 2. Bölümde SKÖ altında bootstrap yöntemine dayalı olarak iki yığın için verilen örnek seçim yöntemleri kullanılarak gerçek veri üzerinde 
uygulama çalışması gerçekleştirilmiştir. $\mathrm{Bu}$ amaçla, Keban Baraj Gölü'nde yaşayan Alburnus mossulensis Heckel 1843 balı türüne ait otolit biyometrisi verileri kullanılmıştır (Bütün, 2013). Balığın yaşını tespit edilebilmek için otolit kemiğinin çıkarılıp gerekli bazı ölçümlerin laboratuvar ortamında yapılması gerekmektedir. $\mathrm{Bu}$ ölçüm hem maliyeti artırmakta hem de balığın ölmesine neden olmaktadır. Ancak, balık boyu ve balık ağırlığının balığın yaşı ile yüksek derecede ilişkili olduğu bilinmektedir (Bütün, 2013). Bu anlamda balık boyu değişkeni dikkate alınarak balığın yaşı tahmin edilebilir.

Uygulamada, balık boyu değişkeni ile ilgilenilmiştir. Mevcut veri eşey bakımından erkek ve dişi olarak iki gruba ayrılmıştır. Küme çapı $m=3$ ve döngü sayıları $r_{1}=r_{2}=4$ olmak üzere, iki grup için seçilen sıralı küme örnekleri Tablo 9'da verildiği gibidir.

Tablo 9. İki grup için $m=3, r_{1}=r_{2}=4$ olarak seçilen Alburnus mossulensis Heckel 1843 balık türüne ait boy $(\mathrm{mm}$.) verileri

\begin{tabular}{|l|l|l|l|}
\hline 126 & 115 & 129 & 118 \\
\hline 117 & 127 & 131 & 127 \\
\hline 129 & 138 & 132 & 148 \\
\hline
\end{tabular}

\begin{tabular}{|l|l|l|l|}
\hline 125 & 118 & 114 & 114 \\
\hline 126 & 117 & 130 & 125 \\
\hline 131 & 126 & 124 & 131 \\
\hline
\end{tabular}

Tablo 9'da verilen örneklere dayalı olarak, 2. Bölümde tanıtılan bootstrap örnek seçim yöntemleri kullanılarak $B=2000$ bootstrap tekrarı ile güven aralığı alt ve üst sınırları elde edilmiştir. GA genişlikleri üst sınır ile alt sınır farkına dayalı olarak bulunmuştur. Ancak, uygulama tek bir örnek verisi üzerinden yapıldığı için GA oranları elde edilememiştir. Sonuçlar Tablo 10'de verilmiştir.

Tablo 10. 1. ve 2. yönteme göre GA alt ve üst sınırları ile GA genişlikleri

\begin{tabular}{|c|c|c|c|}
\hline Yöntemler & Alt sınır & Üst sınır & GA genişliği \\
\hline 1.Yöntem & 0.5833 & 8.8333 & 8.25 \\
\hline 2. Yöntem & 0.3333 & 9.0833 & 8.75 \\
\hline
\end{tabular}

Tablo 10 incelendiğinde, 1. yöntem ile elde edilen GA genişliğinin 2. yöntem ile elde edilen GA genişliğginden daha dar olduğu görülmektedir.

\section{Sonuçlar ve Öneriler}

$\mathrm{Bu}$ çalışmada SKÖ altında farklı Bootstrap yöntemlerinden elde edilecek örnekler kullanılarak, iki yığın ortalama farkına ilişkin güven aralığı kapsama olasılığı ve genişlikleri incelenmiştir. Bunun için öncelikle iki yığın ortalaması farkına iliş̧in güven aralıklarının oluşturulmasında SKÖ'ye dayalı Bootstrap yöntemi altında iki farklı örnek seçim yöntemi geliştirilmiştir. Geliştirilen bu yöntemlerin etkinliklerini araştırmak amacıyla simülasyon çalışması yapılmıştır. Yapılan simülasyon çalışmasında bilinen farklı simetrik ve simetrik olmayan dağılımlar kullanılmıştır. İncelenen tüm dağılımlarda küme çapı ve döngü sayısı arttıkça elde edilen GA oranları artmakta, GA genişlikleri daralmaktadır. Genel olarak GA oranlar1 başlangıçta belirlenen güven düzeyi $\% 95$ 'e yaklaşmaktadır. Ayrıca incelenen simetrik dağılımlar bakımından Standart normal ve Uniform dağılım için 1. ve 2. yöntemle elde edilen GA oranları birbirine yakın olmasına rağmen elde edilen GA genişlikleri incelendiğinde aynı küme çapı ve döngü sayısı için Uniform dağılım ile elde edilen genişliklerin daha dar olduğu görülmektedir. İncelenen simetrik olmayan dağ 1 lımlardan Gamma $(0.5,1)$ ve Gamma $(4,1)$ dağılımları ile elde edilen sonuçlara göre; dağılımın çarpıklığı azaldıkça elde edilen GA oranlarının daha yüksek olduğu görülmektedir. Bu durum Invers Gauss $(1,1.13)$ ve Invers Gauss $(1,9.09)$ için de korunmaktadır. Bununla birlikte, GA genişlikleri değerlendirildiğinde, dağılımın varyansının GA genişliği üzerinde etkili olduğu söylenebilmektedir. İncelenen dağılımlar için, varyansı büyük olan dağılım altında elde edilen GA genişliklerinin varyansı küçük olan dağılım altında elde edilen GA genişliklerinden daha yüksek olduğu görülmektedir. Ayrıca, uygulama çalışması ile elde edilen GA genişlikleri de simülasyon çalışması ile elde edilen sonuçlarla paralellik göstermektedir.

\section{Kaynaklar}

Akgül, F., Şenoğlu, B. ve Acıtaş, Ş., 2018. Interval Estimation of the System Reliability for Weibull Distribution Based on Ranked Set Sampling Data. Hacettepe University Bulletin of Natural Sciences and Engineering Series B: Mathematics and Statistics 47(5):1404-1416. 
Albatineh, A. N., Kibria, B. M. G., Wilcox, M. L. and Zogheib, B., 2014. Confidence Interval Estimation for the Population Coefficient of Variation Using Ranked Set Sampling: A Simulation Study. Journal of Applied Statistics, 41, 733-751.

Bütün, S., 2013. Keban Baraj Gölü'nde Yaşayan Alburnus Mossulensis Heckel, 1843'de Otolit Biyometrisi Yüksek Lisans Tezi, Frrat Üniversitesi Fen Bilimleri Enstitüsü. Elazığ, 43s.

David, H. A. and Levine, D.N., 1972. Ranked Set Sampling in the Presence of Judgment Error. Biometrics, 28, 553-555.

Dell, D. R. and Clutter, J.L., 1972. Ranked Set Sampling Theory with Order Statistics Background. Biometrics, vol. 28 (2), 545-555.

Efron, B., 1979. Bootstrap Methods: Another Look at Jackknife, Institute Of Mathematical Statistics, 7, $1-26$.

Mahdizadeh, M. and Zamanzade, E., 2018. Interval Estimation of $\mathrm{P}(\mathrm{X}<\mathrm{Y})$ in Ranked Set Sampling. Computational Statistics. 33, 1325-1348.
McIntyre, G. A., 1952. A method of Unbiased Selective Sampling Using Ranked Sets. Australian Journal of Agricaltural Research, vol. 3, 385-390.

Modarres, R.; Hui, T. P. and Zheng, G., 2006. Resampling Methods for Ranked Set Samples, Computational Statistics and Data Analysis, 51, 1039-1050.

Patil, G. P., Sinha, A.K. and Taillie, C., 1997. Ranked Set Sampling, Coherent Rankings and SizeBiased Permutations, Journal of Statistical Planning and and Inference, 63, 311-324.

Stokes, S. L., 1977. Ranked Set Sampling with Concomitant Variables. Communications in Statistics, 6, 1207-1211.

Takahasi, K. and Wakimoto, K., 1968. On Unbiased Estimates of the Population Mean Based on the Sample Stratified by means of Ordering. Annals of The Institude of Statistical Mathematics, vol. 21, 249-255.

Yeniay, N., Özdemir, Y. A. ve Gökpınar, F., 2017 Sıralı Küme Örneklemesi Altında Farklı Bootstrap Yöntemleri ile Yığın Ortalaması için Güven Aralığı, Sakarya Üniversitesi Fen Bilimleri Enstitüsü Dergisi, 21-6: 1394-1407, doi.org/10.16984/saufenbilder.295879. 
1. yöntem

EK. Kullanılan algoritmaların MATLAB kodları

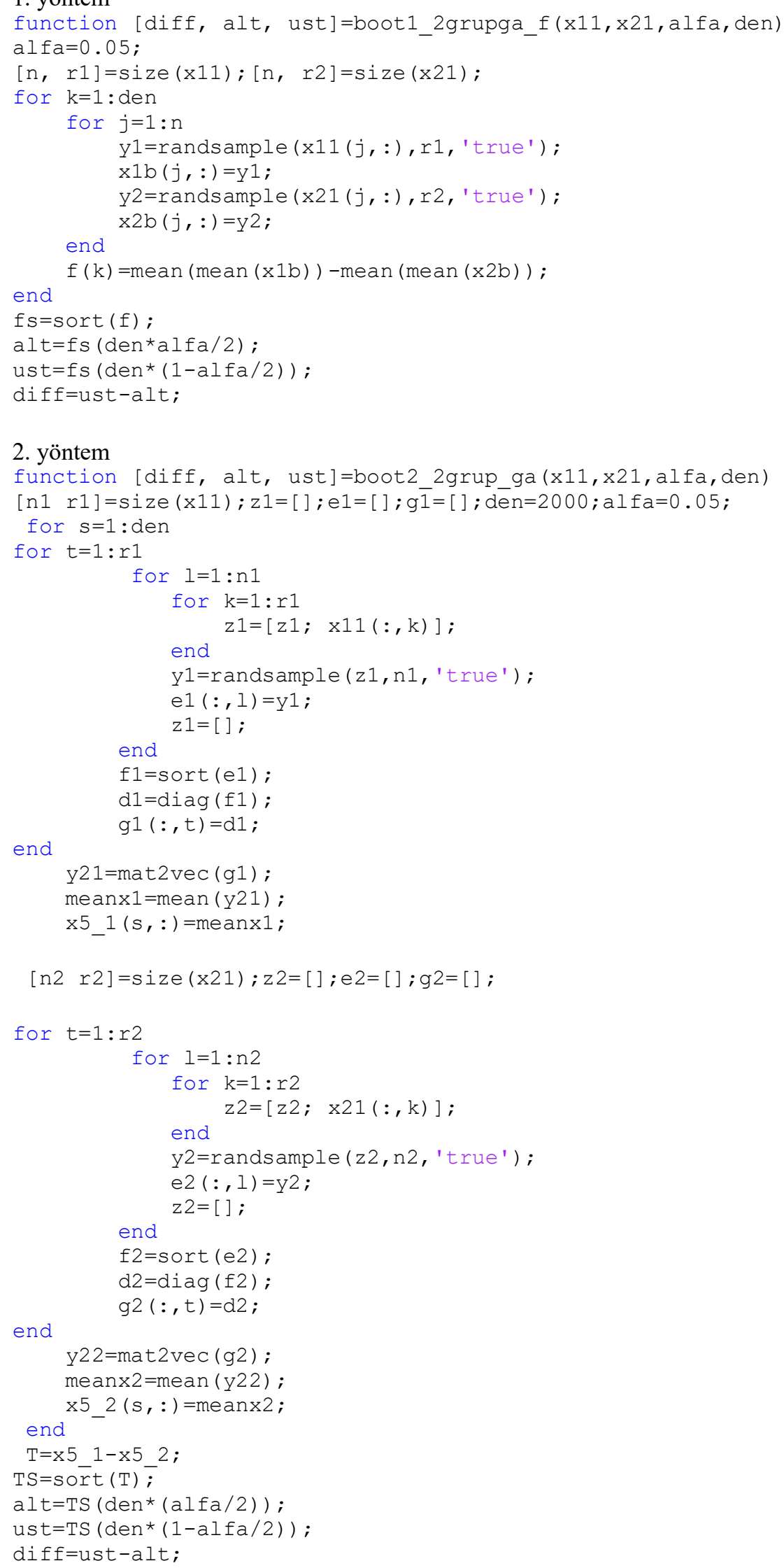

\section{2. yöntem}

function [diff, alt, ust]=boot2 2 grup ga (x11, x21, alfa, den)

[n1 r1] =size $(x 11) ; z 1=[] ; e 1=[] ; g \overline{1}=[] ;$ den=2000; alfa=0.05;

for $s=1:$ den

for $t=1: r 1$

for $l=1: n 1$

for $k=1: r 1$ $\mathrm{z} 1=[\mathrm{z} 1 ; \mathrm{x} 11(:, \mathrm{k})]$; 